\title{
A Clinico-Epidemiological Profile of Neuroparalytic Snake Bite, Using Low Dose ASV in a Tertiary Care Centre from Western Maharashtra
}

\author{
Makrand Mane ${ }^{1}$, Priyanka Makarand Mane², Indranil Kulkarni³ ${ }^{3}$ Tesas Bhosale ${ }^{4}$ \\ ${ }^{1}$ Department of General Medicine, Krishna Institute of Medical Sciences, Karad, Maharashtra, India. \\ ${ }^{2}$ Department of Microbiology, Krishna Institute of Medical Sciences, Karad, Maharashtra, India. ${ }^{3}$ Department \\ of General Medicine, Krishna Institute of Medical Sciences, Karad, Maharashtra, India. ${ }^{4}$ Department of \\ General Medicine, Krishna Institute of Medical Sciences, Karad, Maharashtra, India.
}

\section{ABSTRACT}

\section{BACKGROUND}

According to the World Health Organization, snakebites cause more death and disability and are more notorious than some tropical diseases. Snakebite is a leading medical emergency in Asia/Pacific. It is one of the major causes of mortality in India. The objective of this study was to determine the clinico-epidemiological profile of a neuroparalytic snake bite at the Department of Medicine, Krishna Institute of Medical Sciences, Karad, one of the tertiary care centers of Western Maharashtra, in India.

\section{METHODS}

A descriptive study of 80 patients was carried out at the Department of Medicine, KIMS, Karad, a tertiary care center of Western Maharashtra, India. Present study showed outcome, delay in arrival, and epidemiology of patients with low dose of ASV in neuroparalytic snakebites and ventilator support. Descriptive statistics were shown by using MS Excel and SPSS Version 25.

\section{RESULTS}

Out of 80 cases $56.2 \%$ were males and $43.8 \%$ were females with a mean age of 28.16 years. $63.7 \%$ of the snakebite victims were bitten outside and $85 \%$ of the snakebites occurred on the lower extremity. On an average, 15.24 vials of ASV were administered. $80 \%$ patient were in Intensive Care and they were on ventilator support and $91 \%$ patients recovered from these snake bites. $51.25 \%$ of the patients reached the hospital within the interval of 3-7 hours.

\section{CONCLUSIONS}

Study signifies the importance of snakebite threat to the community. Delay in reaching a hospital in time where snakebite patients can be treated, was the most important cause of death. Public health programs should be strengthened. Administration of Low dose ASV and ventilator support can provide sufficient cure if patients reach on time. Lack of awareness, delay in reaching the hospital, and treatment by non-medical persons are important factors that should to be addressed.

\section{KEY WORDS}

Neuroparalytic, Epidemiology, Snakebite, Anti-Snake Venom, Outcome, Antivenin, Russell's Viper, Haemotoxic, Neurotoxic, Mortality
Corresponding Author: Dr. Makarand Mane, Associate Professor, Department of Microbiology KIMS, Karad, Maharashtra, India.

E-mail: makarand.mane@gmail.com

DOI: $10.14260 / j e m d s / 2020 / 298$

Financial or Other Competing Interests: None.

How to Cite This Article:

Mane M, Mane PM, Kulkarni I, et al. A clinico- epidemiological profile of neuroparalytic snake bite, using low dose ASV in a tertiary care centre from Western Maharashtra. J. Evolution Med. Dent. Sci. 2020;9(16):1369-1372, 10.14260/jemds/2020/298

Submission 31-08-2019, Peer Review 04-04-2020, Acceptance 10-04-2020, Published 20-04-2020.

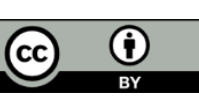




\section{BACKGROUND}

Annually, approximately 125,000 deaths are seen worldwide because of snake bites. ${ }^{1}$ Snake bite is an occupational hazard and common medical emergency in tropical India. About 278 species are found in India out of which 58 species are poisonous (Raut et al., 2014). ${ }^{2}$ Snake bite recognizes as one of the neglected tropical disease according to World Health Organization (WHO). In the world, India has highest around $35,000-50,000$ deaths per annum out of 2,50,000 snake bites incidents observes because of the poisonous snake bites, despite the fact that India is neither home for the largest number of venomous snakes in the world, nor there is a shortage of anti-snake venom in the country. ${ }^{3}$ For the death toll social, cultural, and economic reasons contribute immensely. ${ }^{4}$ In different parts of country with varied distribution of 216 species of snakes, observes in India (Table 1).

\begin{tabular}{|ccc|}
\hline Snake Species & Common Name & Geographical Area \\
Naja naja & Common cobra & Throughout India \\
Hypnale hypnale & HNPV & Western Ghats \\
Ophiophagus & King Cobra & Western Ghats, Andaman and \\
hannah & Nikobar islands \\
Naja sagittifera & Andaman Cobra & Andaman and Nikobar islands \\
Bungarus caeruleus & Common Krait & Kerala, Tamil Nadu and North \\
& eastern Region \\
Bungarus fasciatus & Banded Krait & Andhra Pradesh, Uttarakhand, \\
Daboia russelii & Russell's Viper & and North-Eastern Region \\
Echis carinatus & Saw scaled Viper & South India and western India \\
Trimeresurus & Malabar pit viper & Southwestern India \\
malabaricus & Ghats and western \\
Trimeresurus & Indian Bamboo & South India, Andaman and \\
gramineus & viper & Nicobar Islands \\
Naja kaouthia & Monocellate Cobra & Assam and North-Eastern Region \\
\hline \multicolumn{2}{|c}{ Table 1. Common Snake Species in India (2) } \\
\hline \multicolumn{2}{|c}{}
\end{tabular}

Powered by Maharashtra is a state in the western peninsular of India with 36 districts. Karad is the western part of Maharashtra lying on the conversion of Koyana and Krishna River. Karad has a place with the subtropical classification of atmosphere portrayed by medium to overwhelming precipitation and moderate temperature. In Maharashtra, Species of Cobra, Krait, and Viper are common poisonous snakes found in Maharashtra with their species diversity. Rat snakes (Dhaman), Water snake (Pandivad), Grass snake, Boa's (Mandul, Durkya Ghonas) are nonpoisonous snakes and few snakes have semi-poisonous kind of ability. ${ }^{5}$ By educating people on snake ecology and behaviour, $100 \%$ prevention from snake bites can be done. Respiratory failure (Type II) is vital cause of morbidity and mortality in case of neurotoxic snake. ${ }^{6}$ The main cause of this incidence which can be prevent of snakebite fatalities is that people unawareness and try out all kinds of "bizarre remedies" initially, instead of going to the nearest hospital.

This study aimed to highlight, intensive care with low dose anti-snake venom (ASV) and ventilator, to successfully manage neuroparalytic snake bite.

\section{METHODS}

This is a descriptive, record based study, conducted in the Department of Medicine in a tertiary care hospital of Krishna Institute of Medical Science, in Karad, Maharashtra. A total 80 cases according to convenience have taken from medical record department of the Institute

\section{Sample Collection}

80 Cases of the snakebite victims reached to the hospital for the period of ( $1^{\text {st }}$ December to $31^{\text {st }}$ June) 7 months were obtained from the medical records department. For neurotoxic snake bite, timely administration of ASV along with intensive care and ventilator support is the only effective treatment avialable. ${ }^{7}$ Before reaches venom to the target site Anti-snake Venom is most effective when administered early enough to neutralize the venom in the circulation. About the use of low or high doses of Anti-snake venom there is still no worldwide unanimity about these doses of ASV, but the study regarding the administration of higher dose ( $>20$ vials) over low dose/ conventional-dose found that both are equally efficient. ${ }^{8}$ Entire hospital stay duration for patients follow up were taken during this period. After preparing a detailed proforma, following parameters were recorded \& analysed-

1. Patient parameters (register no, name, age, sex, address, occupation date of admission, ward, clinical features, prior any $\mathrm{T} / \mathrm{T}$ taken, complication developed, and duration of hospital stay).

2. Snakebite characteristics like (bite mark, assessment of bite mark, site, bite to needle time, snake identified by forensic medicine teachers).

3. ASV (time of administration, frequency of administration, dose- loading and maintenance (total) in hospital and outside the hospital, duration, total dose per patient)

\section{Inclusion Criteria}

All patients having age $>11$ years with history of neuroparalytic snake bite.

\section{Exclusion Criteria}

1. Vasculotoxic snake bites (patients with bleeding diathesis and with deranged bleeding time, clotting time or platelets below 100000 per microliter).

2. Patients with renal failure.

\section{Statistical Methods}

Statistics of the study is done by using Descriptive statistics shown by proportion with the help of Microsoft Excel 2010 and SPSS Version 25.

\section{Ethical Considerations}

After approval from the Institutional Ethics Committee (IEC) of the college study was conducted. No Scoring system were used in this study.

\section{RESULTS}

Out of total 80 cases reached and reported to the hospital of venomous snakebite were included in this study, during the 
period of 7 months, demographic presentation is given in table No. 2. In which $56.2 \%$ of cases found to be male and $43.8 \%$ were found to be female. $51(63.7 \%)$ victims of the snake bite were bitten outside and few indoors 29 (36.3\%). For $68(85 \%)$ of snake bite victims bitten site was the lower extremity and in a few over upper extremities 12 (15\%).

In this study sample, victims in the age group of 16-30 years were more which was 47 (58.75\%) followed by 31-45 Years $17(21.25 \%)$. The mean age of overall snake bites victims was 28.16 years. The age-wise distribution of snakebite cases has been shown in Figure 1.

\begin{tabular}{|c|c|c|}
\hline Variables & Frequency & Percentage \\
\hline \multicolumn{3}{|c|}{ Age } \\
\hline$\leq 15$ Years & 7 & 8.75 \\
\hline 16-30 Years & 47 & 58.75 \\
\hline 31-45 Years & 17 & 21.25 \\
\hline$>45$ Years & 9 & 11.25 \\
\hline \multicolumn{3}{|c|}{ Sex } \\
\hline Male & 45 & 56.2 \\
\hline Female & 35 & 43.8 \\
\hline \multicolumn{3}{|c|}{ Location } \\
\hline Outdoor & 51 & 63.7 \\
\hline Indoor & 29 & 36.3 \\
\hline \multicolumn{3}{|c|}{ Site of Bite } \\
\hline Upper Extremity & 12 & 15.0 \\
\hline Lower Extremity & 68 & 85.0 \\
\hline Table 2. Dem & rofiles Snak & ictims \\
\hline
\end{tabular}

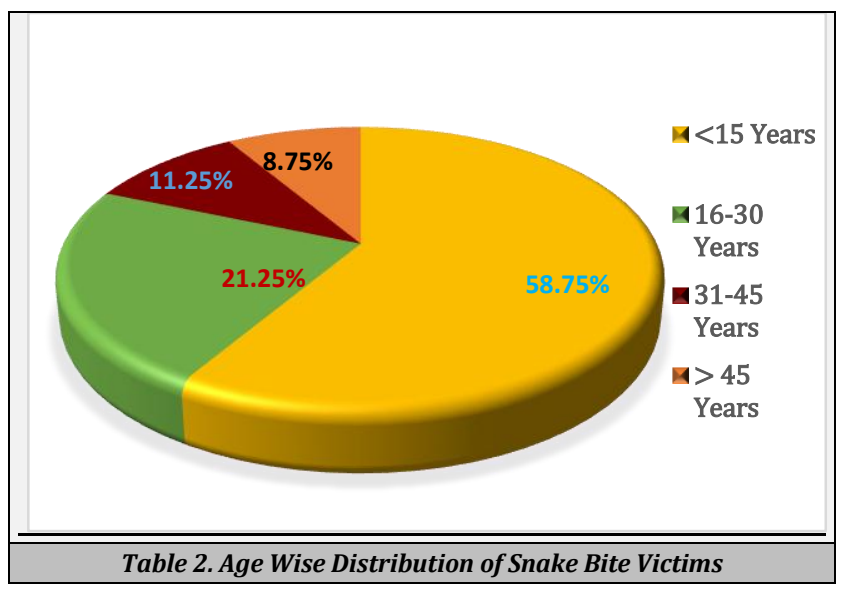

\begin{tabular}{|cccccc|}
\hline $\begin{array}{c}\text { Bite-To-Needle } \\
\text { Time (hr) }\end{array}$ & $\begin{array}{c}\text { No. of } \\
\text { Patients }\end{array}$ & $\begin{array}{c}\text { No. of } \\
\text { Vials }\end{array}$ & $\begin{array}{c}\text { Ventilator } \\
\text { Support }\end{array}$ & Survive & Expired \\
$<3$ & 24 & 7 & $4(16.66 \%)$ & $24(100 \%)$ & $0(0.0 \%)$ \\
$3-7$ & 41 & 15 & $34(82.92 \%)$ & $41(100 \%)$ & $0(0.0 \%)$ \\
$8-10$ & 4 & 20 & $4(100 \%)$ & $0(0.0 \%)$ & $4(100 \%)$ \\
$>10$ & 11 & 20 & $11(100 \%)$ & $8(72.72 \%)$ & $3(27.08)$ \\
\hline Table 3. Patients Distribution According to "Bite-to-Needle Time", \\
Number of Vials Used, Ventilator Support and Outcome \\
\hline
\end{tabular}

The above table shows that 24 patients reached the hospital less than 3 hours of snakebite, all patients survived those who got immediate treatment of 7 vials of ASV and 4 patients were on ventilator support. Between 3-7 hour of snake bites 41 patients reached to the hospital, for all these patients 15 vials of ASV was given (for the first time 10 vials and due to no improvement in respiratory effort again 5 vials were injected) out of 41 patients 34 patients were on the ventilator support to cure respiratory failure, thus the survival rate all of the patients was $100 \%$. Between $8-10$ Hours of snakebite, 4 patients arrived, initially along with ventilation support 20 vials of ASV was given but none of the patients survived. After 10 hours of incidence 11 patients of the total reached to the hospital, along with ventilator support 20 vials of ASV was given but of them, 8 patients survived. From the given above data, rate of survival rate was showing maximum when the patient is reaching to the hospital within 7 hours of snakebite (Table 3).

To Neutralize the venom in the circulation before it reaches the target site, average of 15.23 vials were used to treat all the cases. Among these 53 (66.25\%) patients needed ventilator support for effective treatment. Maximum survival was shown by the patients who were reached to the hospital within 7 hours. With the treatment and cardiorespiratory monitoring, average duration of stay in the hospital was 8.3 days. Out of the 80 patients, $73(91.25 \%)$ survived and 7 $(8.75 \%)$ patients expired because of the lagging in time to reach to the hospital.

\section{DISCUSSION}

In this study, 80 Snake bite cases were recorded from December - June 2018-19 period. Elapidae are some major families of poisonous snakes in India, in which common cobra (Naja naja), king cobra and common krait (B. caeruleus) are found, in Viperidae Russell's viper, Saw scaled or carpet viper (Echis carinatus) and pit viper are observed and Hydrophiidae (sea snakes). ${ }^{9}$ In the venom of Cobra contains cobra toxin and $\alpha$ - bungarotoxin which act post-synaptically by binding to acetylcholine receptors on the motor endplate while $\beta$ bungarotoxin and crotoxin present in krait venom act presynaptically and prevent release of acetylcholine at the neuromuscular junction, resulting in muscle paralysis due to curare like neuromuscular blocking action affecting the muscles of eyes, throat, and chest leading to type II respiratory failure. Respiratory failure was either a result of respiratory muscle paralysis and/or palatal paralysis leading to the accumulation of secretions and aspiration. ${ }^{10}$ Bites were more frequent in males than females, the ratio being approximately $1.3: 1$ as it was observed in equal to studied by Inamdar $\mathrm{K}$ et al. ${ }^{4} 16-30$ years (58.75\%) age group has maximum number of cases of snake bites observed, followed by age group of $31-45$ years $(21.25 \%)$ as it was studied by P.C. Pandey et. al. ${ }^{10}$ In this study, At lower extremities $85 \%$ of bites occurred, which is found an equal proportion in the study done by P.C. Pandey et. al. ${ }^{10}$ In the present study 5.6 hours was the average time required to reach to the hospital after the bite, which was nearly equal by other workers, Harssor (7 hours). ${ }^{11}$

Average ASV dose was 15.23 Vial $(152.3 \mathrm{ml})$ given in this study, in a study conducted by Sharma et al ${ }^{12}$ and Agarwal et al respectively which were $512 \mathrm{ml}$ and $900 \mathrm{ml}$. In our study the total dose and the bolus dose requirement was less than the recommended dose. In the present study, 91\% of patients responded to neostigmine and showed improvement in ptosis and in the rest of the $9 \%$ patient neostigmine was discontinued in view of lack of response. 48.5 hours in this study was the mean ventilation duration which is nearly equal to 48 hours studied by SAM Kularantne. ${ }^{13}$ For snakebite cases this therapy is not always available. ${ }^{14}$ because of nonavailability of transport, poor knowledge to identify snakes and high cost of ASV, In the present study 73 (91\%) patients completely recovered. 7 patients who died, because of the delay in reaching the hospital, because of the poor 
transportation facility this delay in their arrival, the use of local remedies and lack of awareness of the hazards of snakebite were observed in this study. Mean hospital stay for the patients was 8.5 days in which minimum days were 3 and maximum were. ${ }^{13}$

\section{CONCLUSIONS}

Study signifies the importance of snakebite threat to the community. Delay in reaching a hospital in time where snakebite patients can be treated, was the most important cause of death. Public health programs should be strengthened. Administration of Low dose ASV and ventilator support can provide sufficient cure if patients reach on time. Lack of awareness, delay in reaching the hospital, and treatment by non-medical persons are important factors that should to be addressed.

\section{ACKNOWLEDGEMENT}

We thank the patients, medical staff, and the nursing staff, of the study hospital for their cooperation during this study.

\section{REFERENCES}

[1] Chippaux JP. Snake-bites: appraisal of the global situation. Bull World Health Organ 1998;76(5):515-24.

[2] Raut SR, Deshbhratar SM, Jyotsna A, et al. Documentation of road killed and rescued harpatofauna in and around Amravati City, Maharashtra. Advances in Applied Science Research 2014;5(2):373-81.

[3] Kasturiratne A, Wickremasinghe AR, De Silva N, et al. Estimating the global burden of snakebite: a literature analysis and modelling based on regional estimates of envenoming and deaths. PLoS Med 2008;5(11):e218.
[4] Inamdar IF, Aswar NR, Ubaidulla M, et al. Snakebite: admissions at a tertiary health care centre in Maharashtra, India. S Afr Med J 2010;100(7):456-8.

[5] Gangadhar TN, Chavan SP. Snake species diversity of Swami Ramanand Teerth Marathwada University, Nanded, Maharashtra State, India. Int J Curr Res Aca Rev 2016;4(6):104-15.

[6] Mitra S. Snake bite in India and its management. J Indian Med Assoc 1987;85(5):129-31.

[7] Agrawal A, Gupta A, Khanna A. What dose of anti-snake venom should be given in severe neuroparalytic snake bite? Ann Thorac Med 2011;6(1):47-8.

[8] Agarwal R, Aggarwal AN, Gupta D, et al. Low dose of antisnake venom is as effective as high dose in patients with severe neurotoxic snake envenoming. Emerg Med J 2005;22(6):397-9.

[9] Tariang DD, Philip PJ, Alexander G, et al. Randomized controlled trial on the effective dose of anti-snake venom in cases of snake bite with systemic envenomation. J Assoc Physicians India 1999;47(4):369-71.

[10] Pandey PC, Bajaj S, Srivastava A. A clinicoepidemiological profile of neuroparalytic snake bite: using low dose ASV in a tertiary care centre from North India, J Assoc Physician India 2016;64(8):16-20.

[11] Harsoor SS, Gurudatta CL, Balabhaskar S, et al. Ventilatory management of patient with neuroparalytic envenomation. Indian J Anaesth 2006;50(6):452-5.

[12] Sharma N, Chauhan S, Faruqi S, et al. Snake envenomation in a north Indian hospital. Emerg Med J 2005;22(2):118-20.

[13] Sanmuganathan PS. Myasthenic syndrome of snake envenomation: a clinical and neurophysiological study. Postgrad Med J 1998;74(876):596-9.

[14] Howarth DM, Southee AE, Whyte IM. The lymphatic flow rates and the first aid in simulated peripheral snakes or in spider envenomation. Med J Aust 1994;161(1112):695-700. 